\title{
The Role of Countries of Origins, Attitudes, Buying Intention and the Self-Esteem in Smartphone Usage
}

\author{
Tien Chin Wang, Yen Ying Huang* \\ Email address: \\ tcwang@kuas.edu.tw (Tien Chin Wang), yenhuang1976@gmail.com (Yen Ying Huang) \\ ${ }^{*}$ Corresponding author
}

Department of International Business, National Kaohsiung University of Applied Sciences, Kaohsiung City, Taiwan

To cite this article:

Tien Chin Wang, Yen Ying Huang. The Role of Countries of Origins, Attitudes, Buying Intention and the Self-Esteem in Smartphone Usage. International Journal of Business and Economics Research. Vol. 7, No. 4, 2018, pp. 110-118. doi: 10.11648/j.ijber.20180704.15

Received: June 21, 2018; Accepted: August 2, 2018; Published: August 13, 2018

\begin{abstract}
Consumers' behaviors are easily influenced by inner factors such as attitudes, intentions, and self-esteem, and by external factors like country of origin. It's crucial for businesses to grasp the changing of behaviors in consumers when facing the competition and the ever-changing environment. This research, choosing smartphones market as the target, use the methodof experimental design and takes consumer self-esteem asthe intervening variable to conduct a survey with 400 subjects coming from five cities in Taiwan (Taipei, New Taipei, Taichung, Tainan and Kaohsiung). This research, targeted at smartphones, aims to understand how the brand operators confront with the competition among their own brands and other local or foreign brands, and further overcome the difference of purchasing behavior among targeted consumers, and strengthen its channel management, finally maintaining the market share. The results show that the country of origin of a smartphone brand has a certain extent of influence on consumers' attitude, buying intentions, and self-esteem. The consumer enjoys the unique experience with higher self-esteem, and since one of the components building up the self-esteem is "Selfhood", which means a feeling of individuality or awareness of unique qualities. It is hoped that this study may provide the evidence-based approach for academic research and associated industries, and further become a feasible reference being applied in other research fields.
\end{abstract}

Keywords: Countries of Origins, Consumers’ Attitudes, Buying Intentions, Consumers’ Self-Esteem

\section{Introduction}

With the market globalization and rapid economic growth, pursuing the prosperity and improvementhave become the mission of operating a business. Thus, it'scrucial to develop an accurate marketing strategy by understanding the mentality of consumers and strengthening the ability of the business to grasp consumers' behaviors. Therefore, this study, targeted

at smartphones, aims to understand how marketers face the competition among their own brands and other local and foreign products, and further overcome the difference of purchasing behavior between targeted consumers to be able to maintain its market share.

In addition, products' country of origin has a chance to influence consumers' judgment about the source of the product and their buying decision. This research presents that "Country-Of-Origin Effect"for having a steady influence on the consumers' judgment about the product's quality, and the image of the product, which affects consumers' awareness of the "product attribute" thecompany has made [1]. AsHan argued, when the consumer is lacking in the familiarity with products, or the motivation to figure out products' information, the "Country-Of-Origin Effect"becomes a factor influencing consumers' perceptions about the products' quality [2]. Furthermore, the consumers often assess the value of a product by subjective perspective rather than objective knowledge and information. Many studies have found that consumers' evaluation of general products, specific categories of products or brands, are influenced by the "Country-Of-Origin Effect" [1].

The focus of marketing research has shifted from the transaction to the relationship, emphasizing the importance of marketing and the marketing strategiesbased on long-term 
orientation to manage their consumers [3, 4]. Hence, the business has a good grasp of consumers' mentality and buying behaviors, so after a complete planning of marketing strategies they can choose the best one, making the most benefits from it, and becoming the leading brand in the market.

The purpose of this research is to explore the moderation effect of consumers' self-esteem through aspects like the "Country-Of-Origin Effect", the correlation between consumers' attitude and buying willingness and so on, adopting evidence-based practice to discuss how "Country-Of-Origin Effect" affects consumers' buying behaviors, and the degree of influence on consumers' attitude.

\section{Literature Review}

\subsection{Country of Origin}

Nagashimadefined the country of origin in his research: the image, reputation, and stereotype that consumers and companies give to a product from a particular country [5]. In addition, the "Country-Of-Origin Effect" is also known as consumers' perceptions and attitudes toward a product or a brand of a particular country [6, 1, 2, 7]. Furthermore, consumers' perceptions toward a product's features and their judgments about product quality are influenced by the image of a country [1].

Hong and Wyer found in their research by the design of experiments that the image of a country influences consumers easily by presenting them with a stereotype, especially in the face of an unfamiliar product[8]. On the contrary, if the consumer has already been equipped with knowledge and user experience of the product, their evaluation of a familiar product won't be influenced by the "Country-Of-Origin Effect". Roth and Romeo pointed out in their study in 1992 that consumers' perception of a product of a particular country is formed by how the consumer thinks about the ability of a specific country to manufacture a product or their marketing of a product [7]. In addition, the national stereotype is a set image and idea that people of a nation have about what people or products of another nation are like Johansson, Douglas, and Nonaka's study [9].

In the study in 1988, Han andTerpstracategorized the attribute of country of origin into "the country of manufacture" and "the country of brand", and they found both of them influence consumers' evaluation of the product, but the country of manufacture made a more obvious impact on it [10]. Following the study [11], Chao pointed out in 1993 that the trend of global marketing leads to the mixed product (referring to a product manufactured by two or more countries), and this study expanded the categories of country of origin, including the four: "country of brand," "country of design," "country of assembling", and "country of components." Consumer chooses a brand who use the ethnocentrism knowledge and product information about the producer country of origin [12].

Product information is divided into two attributes: internal and external attribute. The internal attribute refers to the composition of the product, such as taste or ingredient, and the external attribute means the characteristic beyond the product itself, like prices, mark, packaging, and distribution channels. Consumers rely on external attributes to evaluate products when they don't have sufficient product knowledge to assess the internal attributes or if the overall difference among products isn't obvious $[13,9]$. As some scholars argue, the higher the consumer's evaluation of a product, the higher the level of economic development on behalf of the country of origin. There is a positive correlation between the two, so when a product is from the region or country with higher degree of economic development, the consumer givesa higher evaluation score to the product and show more buying intention [14-16]. According to the previous studies, there is a positive correlation between the country of origin and the perceived quality of the consumer, influencing the consumer's perception and evaluation of the product, which has become an important reference for consumers to evaluate the value of the product. Furthermore, it implies that the "Country-Of-Origin Effect" affects the consumer's beliefs and attitudes toward products or services, having a further impact on the buying intention and behavior [17].

According to the mentioned literatures, the author proposed the hypothesis used in this study:

H1: The product or the brand with good image of country of origin has a positive impact on consumers' attitudes.

$\mathrm{H} 2$ : The product or the brand with good image of country of origin stimulates the buying intention of the consumers.

\subsection{Consumers' Attitudes}

According to the study provided by [18], attitude is an inclination, a consistent state of like or dislike results from observing a given object. In addition, Rosenbergand Hanland have defined that attitude consists of three aspects: cognitive component, affective component, and conative component [19]. The cognitive component means the belief that an individual owns to certain things, and the affective component refers to a person's subjective feeling of like or dislike, and the conative component depicts the intention of an individual to act according to his or her own beliefs.

Kotler argues that attitudes mean that a person has a persistent evaluation including like or dislike or emotions and behavioral tendencies for certain objects or ideas [20]. Scholars also have found that the attitude of the consumer against an object is mainly from the specific attributes of the product and from other consumers' evaluation of the attributes of these products [18].

Consumer are always influenced by Facebook moderator's comments when they booking hotel on the web [21]. For [22], stable attitude comes from consumers to strike a balance between cognition and emotion; if consumers encounter a state of imbalance, they will find ways to change the current status to achieve the state of balance and stability. He pointed out that the advertisement or promotional tool of products or brands will form a variety of emotions and judgments for consumers, which emotions form the consumers" "feelings" and judgments form the "cognition". These feelings and 
judgments will affect the consumers' belief and attitude toward an advertisement and finally influence their overall attitude towards a brand.

\subsection{Consumers' Buying Intentions}

In 1984, Engel, Blackwell, and Miniardargue that in order to meet their needs the consumer driven by their demands search for information related to the product according to their own experience and the impact of the external environment, assessing all possible alternatives, and making a decision to buy a commodity after comparison, that is, buying behavior is a psychological decision-making process [23]. Brand trusting form a customer emotional commitment and positive impact on customer loyalty, purchasing intentions. [24]

Kotlerindicated two aspects influencing buying intentions [20]. One is other people's attitude, like complying with the expectations of others, or caring about others having negative attitude on their own preferences. The other is a situational factor which is difficult to evaluate. Consumers' buying intentions consist of the expected price, expected product interests and others; so when consumers buy products or services, a situational factor difficult to predict may suddenly appear, which will influence the buying intention, and then change the purchase intention.

Monroe and Chapman proposes that consumers' buying decisions depend on them measuring the perception of the quality or benefit acquired from the product against the price paid as a sacrifice, that is, the relation between perceived benefit and perceived costs [25]. When the perceived benefit is greater than the perceived costs, the greater the consumer's perceived value of the product, and the higher the degree of satisfaction, the stronger the intention to buy.

According to the literatures above, the hypothesis used in this study having to be proven is as follows:

H3: The product or the brand with good image of country of origin has a positive impact on consumers' buying intentions.

\subsection{Consumer's Self-Esteem}

Zillmannand Knoblochproposed the concept of mood management, pointing out that the consumers have the needs to maintain a positive mood $[26,27]$. When the consumer face frustrated emotions, they will choose to accept or buy hedonistic products or services to enhance positive emotions. "Self-enhancement" was defined by [22], Learyand Baumeisteras a situation when consumers face a situation of decreasing self-esteem enhancing their self-esteem to strike a balance to meet their personal needs [28]. Customer's positive self-views are threatened, improved self-esteem will increase consumers on social media, participate in Word-of-mouth intentions, and to enhance the self-enhancement. [29]

Other research indicated that the consumers in United States have a tendency to purchase symbolic products to manifest themselves, and the low self-esteem drives people with low revenue to buy products with high-statue meaning. The interaction between the product and the ability of a consumer making a comparison in the society will be expressed in the ways of consumers' self-esteem states or moods, affecting their buying intentions [30].

According to associated literatures, the following is the hypothesis having to be verified and used in this study:

H4: Consumers' self-esteem makes them care about the image of the country of origin, resulting in the consumer possessing a positive attitude and affecting the buying intention.

\subsection{Structure of the Research}

The purpose of this research is to explore how the "Country-Of-OriginEffect" influences consumers' attitudes and buying intentions and the interference effect resulting from consumers' self-esteem. There are four dimensions gathered from the literature review, the second part of this research, and research hypothesis. A picture of the whole research structure is depicted in Figure 1.

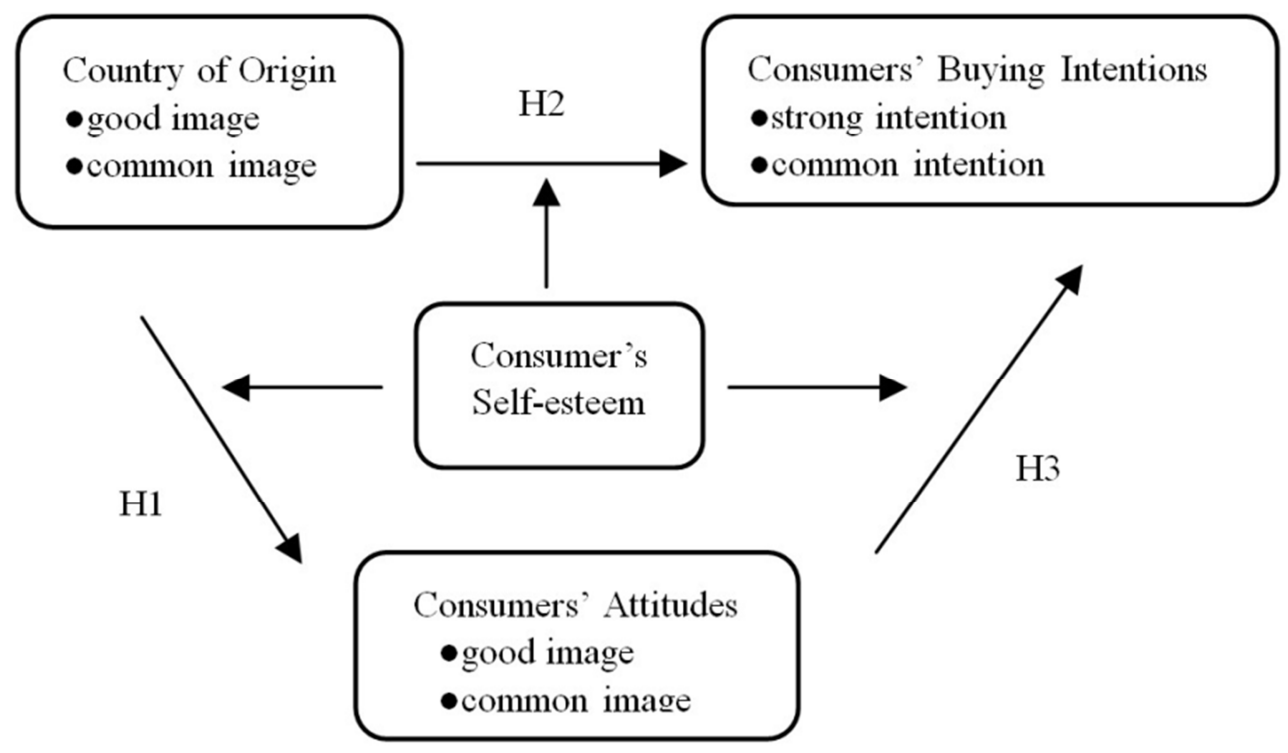

Figure 1. Research structure. 


\section{Method}

The structure and related variables of this research are confirmed according to the literature review, the second part of this research, and then the experiment to carry out the topic of this research, which are alldesigned as the following.

\subsection{Definition of Variables}

According to the research structure, this research uses independent variable, country of origin (classified into two factors: the good image and the general image), intermediate variable, consumers' attitude (classified into the good attitude and the general attitude), intervening variable, consumer's self-esteem, to evaluate the dependent variable, the consumer's buying intention.

The definitions of each variable are the following:

(1) Independent variable: "country of origin," refers to the country (region) which produces, manufactures or imports the original brands (products).

(2) Intermediate variable: "consumers' attitude," refers to consumers' perceptions and the level of emotions of a brand (product), and the higher the positive level, the higher the chance resulting in positive consumer behaviors.

(3) Intervening variable: "consumer's self-esteem," refers to the consumer's self-esteem influenced by the comparative behaviors on the society (which is the state/levelof self-esteem, temporarily influenced by the social condition).

(4) Dependent variable: "the consumer's buying intention," refers to the chance a consumer buys a product. The stronger the buying intention, the higher the chance of buying.

\subsection{Design of Experiments}

According to the literature review and the scheduled cases in this research, consumer's self-esteem will affect their buying intentions and the access to the product. In addition, the "Country-Of-Origin Effect" plays an intermediary role in whether it influences consumers' attitudes during the purchasing process, which must be verified. Through the experimental method, the study operates one or more variables in the controlled situation to determine the effect resulting from these variables. In this research, factorial experiments is adopted to understand the effect of tested variables and to understand the main effects and interactions of each factor.

This research uses independent variable "country of origin" (classified into two factors: the good image and the general image), intermediate variable "consumers" attitude" (classified into the good attitude and the general attitude), and intervening variable "consumer's self-esteem" to evaluate the dependent variable "the consumer's buying intention," applying the "between-subjects and within-subjects experimental method" to determine two experimental groups, which resulted from 2 (country of origin, classified into the good image and the general image) X1 (Consumer's Self-esteem $)=2$, choosing smartphones as the product used in this research. Additionally, the selected subjects only attend the experimental group determined randomlyby draw lots to further validate the research results.

Table 1. Experimental group.

\begin{tabular}{llll}
\hline Group & Country of origin & Consumer's self-esteem & Product \\
\hline 1 & Good image & Consumer's self-esteem & Smartphone \\
2 & Common image & Consumer's self-esteem & S \\
\hline
\end{tabular}

\subsection{Survey and Questionnaire Design}

This research aims at subjects from Taiwan's five special municipalities, Taipei, New Taipei, Taichung, Tainan and Kaohsiung, choosing two universities in each of the municipality with suitable targeted group of consumers. There are a total of 10 universities with 40 subjects in each experimental group, having 400 subjects in the amount attending the test.

The questionnaire of this research was designed according to the summary of previous literature reviews, and the formal questionnaire was distinguished to two versions representing each experimental group. Except the experimental factors in two variables, country of origin and consumers' self-esteem, remaining contents of the questionnaire of two versions are all the same. The questionnaire includes 5 parts, in which part 1 to part 4 were designed according to the four dimensions showed in the research structure, adopting five-point Likert scale (summative scales) to design the content, and part 5 is the background information of the interviewee.

The analysis used the SPSS statistical software, applying methods as follows:

(1) Data Encoding: Examine collected questionnaires and eliminate those filled incompletely.

(2) Number each question and answer in order using Arabic numerals and add them into the file which the statistical software is used in analysis.

(3) Descriptive statistics analysis: Descriptive statistics are used to analyze the distribution of the variables, described by frequency distribution table, the mean, the standard deviation, the percentage and the maximum values of the variables on the basis of subjects' background information and dimensions of the questionnaire, and the questionnaire is designed by adopting five-point Likert scale (summative scales).

(4) Reliability Analysis: To verify the internal consistency of each dimension, and to confirm whether they are consistent with the proposed dimension in the literature review. 
(5) Validity Analysis: To examine the validity of adopted content of the scales and dimensions.

(6) Pearson Correlation Analysis: To estimate the relationship between two variables and to further understand whether there is no correlation between the variables, or to understand the extent of correlation.

(7) Regression Analysis: To discover how independent variables influence dependent variables and the causality or relationships among variables.

\section{Empirical Results}

Questionnaires were used to collect data in this study. The research sent out 400 questionnaires and a total of 364 valid questionnaires returned. The response rate was $91 \%$.

\subsection{Descriptive Statistics Analysis}

A total of 191 females represented for $52.5 \%$ of the subjects. Most subjects were 19-25 range of age, accounting for $42 \%$ as many as 153 people of the subjects. The marital status of the majority was married, which is up to 206 people and accounted for $56.6 \%$ of subjects. 108 subjects now living in the northern region accounted for $29.7 \%$; Up to 113 people with the average monthly income of 10,000 NTD accounted for $31 \%$ of the subject; The average range of cost of smart phone replacement, from 4,001 to $6,000 \mathrm{NTD}$, accounted for $26.6 \%$ with a number of 97 people, and, lastly, the majority of the subjects, accounting for $43.4 \%$ as many as 158 people of the subjects, didn't once replace their mobile phone annually, as shown in Tables 2 below.

Table 2. Background information of the subject.

\begin{tabular}{|c|c|c|c|}
\hline & Item & Number of subjects & Percentage (\%) \\
\hline \multirow{2}{*}{ Gender } & Man & 173 & 47.5 \\
\hline & Weman & 191 & 52.5 \\
\hline \multirow{3}{*}{ Age } & 19-25years old & 153 & 42.0 \\
\hline & 26-35years old & 113 & 31.0 \\
\hline & 36-45years old & 98 & 26.9 \\
\hline Marital status & married & 206 & 56.6 \\
\hline \multirow{4}{*}{ Location } & northern region & 108 & 29.7 \\
\hline & middle region & 66 & 18.1 \\
\hline & southern region & 90 & 24.7 \\
\hline & eastern region & 100 & 27.5 \\
\hline \multirow{3}{*}{ Monthly income } & below10,000 & 113 & 31.0 \\
\hline & $10,001-20,000$ & 84 & 23.1 \\
\hline & $20,001-30,000$ & 93 & 25.5 \\
\hline \multirow{5}{*}{ The average cost of smartphone replacement } & below3,000 & 46 & 12.6 \\
\hline & $3,001-4,000$ & 79 & 21.7 \\
\hline & $4,001-6,000$ & 97 & 26.6 \\
\hline & $6,001-8,000$ & 82 & 22.5 \\
\hline & 8,001 up & 60 & 16.5 \\
\hline \multirow{3}{*}{ The average times of smartphone replacement } & None & 158 & 43.4 \\
\hline & One & 120 & 33.0 \\
\hline & Two & 86 & 23.6 \\
\hline
\end{tabular}

\subsection{Factor Analysis and Reliability Analysis}

Principal component analysis chose correlated factors and used orthogonal rotation (varimax) to extract the factor loading matrix and to compute the eigenvalue. If the eigenvalue is $>1$, the loadings for all variables are $>0.3$, and the cumulative variance up to $40 \%$; this factor can be seen as stable [29]. Besides, Cronbach's alpha is a coefficient to measure the degree of consistency of the questionnaire. The higher the coefficient, the better the reliability, and the coefficient should be 0.7 or more, not less than 0.35 . Cronbach's $\alpha$ value in this study were $>0.7$, showing that the study questionnaire has good reliability [28], as shown in the Table 3 to Table 5.

a. Country of origin

This dimension has a total of 10 question items, using factor analysis to extract two factors and removing three questions (as Table 3). The eigenvalue of each factor was $>1$, the cumulative variance was $58.691 \%$, and the Cronbach's $\alpha$ value was $>0.7$, indicating that the factors were considered reliable.

b. Consumers' attitudes

This dimension has a total of 10 question items, using factor analysis to extract two factors and removing three question items (as Table 4). 5 items left in the factor of "good image" and 2 in the "general image". The eigenvalue of each factor was 2.738 and 1.983 respectively, the cumulative variance was $48.279 \%$, and the Cronbach's $\alpha$ value was $>0.6$, indicating that the factors were considered reliable.

c. Consumers' buying intentions

This dimension has a total of 10 question items, using factor analysis to extract two factors and removing three question items (as Table 5). The eigenvalue of each factor, both $>1$, 
was 3.978 and 3.623 respectively, the cumulative variance was $76.397 \%$, and the Cronbach's $\alpha$ values, both were $>0.7$, were 0.861 and 0.821 , indicating that the factors were considered reliable.

The types of validity included Content Validity, Criterion-Related Validity, Construct Validity and
Nomological Validity. As the evaluation of questionnaire in this research was based on the theory, using the similar questionnaire and evaluation items of domestic and foreign scholars' as the reference, which are well-developed and mature scale, so the "content validity" was considered to achieve the best degree of validity in this research.

Table 3. Factor analysis- country of origin.

\begin{tabular}{|c|c|c|c|c|c|c|c|}
\hline Dimension & Factor & The content of question items & Factor loading & Eigen -value & Cumulative variance & Item to total & $\alpha$ value \\
\hline \multirow{7}{*}{ Countryoforigin } & \multirow{4}{*}{ Goodimage } & 7. & 0.851 & \multirow{4}{*}{3.581} & \multirow{4}{*}{30.812} & 0.632 & \multirow{4}{*}{0.891} \\
\hline & & 10. & 0.829 & & & 0.781 & \\
\hline & & 9. & 0.916 & & & 0.763 & \\
\hline & & 8. & 0.841 & & & 0.629 & \\
\hline & \multirow{3}{*}{$\begin{array}{l}\text { Common } \\
\text { image }\end{array}$} & 4. & 0.863 & \multirow{3}{*}{2.712} & \multirow{3}{*}{58.691} & 0.581 & \multirow{3}{*}{0.782} \\
\hline & & 3. & 0.851 & & & 0.565 & \\
\hline & & 2. & 0.743 & & & 0.627 & \\
\hline
\end{tabular}

Note: The content of question items details:

7. The development and design of foreign products is more progressive

10. The product quality of foreign brands is better.

9. The advertising of foreign products is more novel.

8. Foreign products provide more special designs to choose.

4. I like to have some great atmosphere in life.

3. I like diverse range of things.

2. I prefer the term "localize" to "internationalize".

Table 4. Factor analysis- consumers'attitudes.

\begin{tabular}{|c|c|c|c|c|c|c|c|}
\hline Dimension & Factor & The content of question items & Factor loading & Eigen-value & Cumulative variance & Item to total & $\alpha$ value \\
\hline \multirow{7}{*}{$\begin{array}{l}\text { Consumers' } \\
\text { attitudes }\end{array}$} & \multirow{5}{*}{ Good image } & 9. & 0.682 & \multirow{5}{*}{2.738} & \multirow{5}{*}{28.465} & 0.482 & \multirow{5}{*}{0.659} \\
\hline & & 1. & 0.690 & & & 0.497 & \\
\hline & & 2. & 0.756 & & & 0.462 & \\
\hline & & 6. & 0.729 & & & 0.502 & \\
\hline & & 5. & 0.794 & & & 0.437 & \\
\hline & \multirow{2}{*}{$\begin{array}{l}\text { Common } \\
\text { image }\end{array}$} & 4. & 0.687 & \multirow{2}{*}{1.983} & \multirow{2}{*}{48.279} & 0.477 & \multirow{2}{*}{0.625} \\
\hline & & 10. & 0.658 & & & 0.502 & \\
\hline
\end{tabular}

Note: The content of question items details:

9. When my classmates or friends use a traditional phone, I will tell him/her the features and modules of my smartphone.

1. You see the smartphone as an important friend in your life.

2. You think that carrying the smartphone can show personal style.

6. I use smartphone to change my mood when I feel down.

5. When I do something well, I buy a new smartphone as a reward to myself.

4. I choose the smartphone according to the overall quality it presents.

10. When I find my classmates or friends own a better smartphone, I feel my ability or achievement isn't good enough.

Table 5. Factor analysis- consumers 'buying intentions.

\begin{tabular}{|c|c|c|c|c|c|c|c|}
\hline Dimension & Factor & The content of question items & Factor loading & Eigen-value & Cumulative variance & Item to total & $\alpha$ value \\
\hline \multirow{6}{*}{$\begin{array}{l}\text { Consumers' buying } \\
\text { intentions }\end{array}$} & & 2. & 0.785 & \multirow{3}{*}{3.978} & \multirow{3}{*}{42.973} & 0.753 & \multirow{3}{*}{0.861} \\
\hline & Strong & 5. & 0.792 & & & 0.795 & \\
\hline & intention & 9. & 0.852 & & & 0.824 & \\
\hline & \multirow{3}{*}{$\begin{array}{l}\text { Common } \\
\text { intention }\end{array}$} & 10. & 0.941 & \multirow{3}{*}{3.623} & \multirow{3}{*}{76.397} & 0.829 & \multirow{3}{*}{0.821} \\
\hline & & 5. & 0.835 & & & 0.861 & \\
\hline & & 1. & 0.802 & & & 0.782 & \\
\hline
\end{tabular}

Note: The content of question items details:

2. The accumulated brand image showed in the advertisement content can't dispel my mind about buying another brand.

5. A good impression on other brand's smartphones is already formed in my mind.

9. I discuss the models I prefer with my friend when buying the smartphone shown on the advertisement.

6. I often learn brand information from the advertisement content of the smartphone brand.

10. I often observe the changing of smartphone brands by noticing the advertisements of other sales channels.

5. A good impression on other brand's smartphones is already formed in my mind.

1. Except the brands shown in the advertisement, there are many other good brands to choose.

4. I'm thinking of changing to another brand of smartphone. 


\subsection{Analysis of Correlation}

Correlation analysis indicated that "buying intentions," "consumers' attitudes" and "consumers' self-esteem" reached the significant level, showing a high correlation among variables, where the "buying intentions" and "consumers' attitudes" had the highest correlation coefficient, 0.827 , the second highest value, 0.801 , was from the correlation between "buying intentions" and "consumers' self-esteem," the correlation coefficient between "consumers' attitudes" and "consumers' self-esteem" was 0.791 .

Table 6. Analysis of correlation coefficient of consumers'buying intentions, attitudes and self-esteem.

\begin{tabular}{llll}
\hline & Consumers'buyingintentions & Consumers'attitudes & Consumers'self-esteem \\
\hline Consumers' buying intentions & 1 & & \\
Consumers' attitudes & $0.827^{* *}$ & 1 & 1 \\
Consumers' self-esteem & $0.801^{* *}$ & $0.791^{* *}$ & 1 \\
\hline
\end{tabular}

*means p-value $<0.05$; * means p-value $<0.01$;

$* * *$ means p-value $<0.001$

\subsection{Regression Analysis}

a. The impact of consumers' attitudes on consumers' buying intentions

About how consumers' attitudes influence the buying intentions, the regression coefficient is 0.794 and the p-value 0.000 were highly significant, indicating H3 was supported.

Table 7. Regression analysis of consumers' buying intention and attitudes.

\begin{tabular}{llllll}
\hline \multirow{2}{*}{ Variable } & \multicolumn{2}{l}{ Unstandardizedcoefficients } & Standardized coefficients & \multirow{2}{*}{ t value } & \multirow{2}{*}{ Significance } \\
\cline { 2 - 5 } & B value & Standard error & $\beta$ & 7.001 & .000 \\
\hline (Constant) & .738 & .105 & .827 & 27.975 & .000 \\
Consumers' attitudes & .794 & .028 & & $\beta$ & \\
\hline
\end{tabular}

Note: 1 . Dependent variable: Consumers' buying intention

2. *means p-value $<0.05 ; * *$ means p-value $<0.01$;

$* * *$ means p-value $<0.001$.

b. The impact of consumers' attitudes and self-esteem on their buying intentions

In terms of the impact of consumers' attitudes and self-esteem on their buying intentions, the regression coefficient was 0.497 , and the p-value of 0.000 were highly significant, indicating the consumer's self-esteem had a significant impact on consumers' attitudes and their buying intentions.

Table 8. Regression analysis of consumers' buying intention, attitudes andself-esteem.

\begin{tabular}{lllll}
\hline \multirow{2}{*}{ Variable } & \multicolumn{2}{l}{ Unstandardizedcoefficients } & \multicolumn{2}{l}{ Standardized coefficients } \\
\cline { 2 - 5 } & B value & Standard error & $\beta$ & Significance \\
\hline (Constant) & .361 & .104 & & 3.461 \\
Consumers'attitudes & .497 & .042 & .517 & .001 \\
Consumers'self-esteem & .398 & .045 & .391 & .000 \\
\hline
\end{tabular}

Note: 1 . Dependent variable: Consumers' buying intention

2. *means p-value $<0.05 ; * *$ means $\mathrm{p}$-value $<0.01$;

$* * *$ means p-value $<0.001$

c. The effect of consumers' self-esteem on consumers' attitudes buying intentions

The regression coefficient of consumers' attitudes and self-esteem was-.079, and the p-value of 0.000 were highly significant, showing H4 was supported.

Table 9. The interference effect of consumers'self-esteem, attitudes and buying intention.

\begin{tabular}{llllll}
\hline \multirow{2}{*}{ Variable } & \multicolumn{2}{l}{ Unstandardizedcoefficients } & Standardized coefficients & \multirow{2}{*}{ t value } & \multirow{2}{*}{ Significance } \\
\cline { 2 - 5 } & B value & Standard error & $\boldsymbol{\beta}$ & 5.073 & .000 \\
(Constant) & .948 & .187 & .475 & 10.699 & .000 \\
Consumers' attitudes & .457 & .043 & .291 & 5.731 & .000 \\
Consumers' self-esteem & .296 & .052 & -.169 & -3.756 & .000 \\
Consumers' attitudes and self-esteem & -.079 & .021 & & \\
\hline
\end{tabular}

Note: 1. Dependent Variable: Consumers' Buying Intention

2. *means p-value $<0.05$;**means p-value $<0.01$;

$* * *$ means p-value $<0.001$. 


\section{Conclusion}

\subsection{Management Implications}

This research, targeted at smartphones, aims to understand how the brand operators confront with the competition among their own brands and other local or foreign brands, and further overcome the difference of purchasing behavior among targeted consumers, and strengthen its channel management, finally maintaining the market share.

Attitude is consist of perceptions, emotions, and intentions of behaviors, which refers to the consumer taking actions based on their emotional evaluation coming from their knowledge and perception of the product. According to the findings in this research, consumers' attitude will improve their buying intentions, which are consistent with the study of [25]. He argued that consumers' buying decisions depend on how they feel about the quality or benefit of a product and the consumer measures these feelings against the paid price, which is considered as a sacrifice, that is, the relation between perceived benefit and perceived costs. When the perceived benefit is greater than the perceived costs, the greater the consumer's perceived value of the product, and the higher the degree of satisfaction, the stronger the intention of buying.

The forming of the attitude is deeply influenced by the effects or impacts of personal experiences, family, friends, and media. The research result leads us to believe that consumers' self-esteem exerts the effect on consumers' attitudes and their buying intentions, which is consistent with the study of [30]. Their study stated that when a consumer meets a threat or damage to their ego, they have a tendency to purchase a symbolic product to manifest themselves, what more, low self-esteem drives people with low revenue to buy products with high-statue meaning. Therefore, when it comes to promoting a smartphone or telecommunication service, the strategy strengthening the bind and communication among consumers' original perception and self-esteem should be used to enhance consumers' positive attitude and further improve the sales volume.

\subsection{Research Recommendations}

The results showed that consumers' self-esteem has an effect on consumers' attitude and buying intentions. The consumer enjoys the unique experience with higher self-esteem, and since one of the components building up the self-esteem is "Selfhood", which means a feeling of individuality or awareness of unique qualities. Therefore, this research considered celebrity marketing, which uses advertisement or endorsement from a celebrity, or word-of-mouth marketing online as useful strategies adopted in smartphone marketing, which can substantially increase the visibility and enhance consumers' buying intentions out of their demand for self-esteem. Moreover, it is important to put strong emphasis on the function and uniqueness of smartphones, so that consumers think that using this phone will distinguish them from other consumers and enjoy the feeling of bathing in the high-tech world, further increasing their buying intentions in the future.

Finally, consumers' self-esteem is the only intervening variable in this study, however, many factors such as degree of involvement, buying motivation, and trust in a brand or product, relative to the ever-changing society and consumer habits, make real impacts on consumer's attitudes and buying intentions, affecting the consumer's buying intentions. An area for future research will be in the refinement of approaches to the analysis of the relevant factors.

\section{References}

[1] Bilkey. W. J., and E. Nes, "Country-of-Origin effects on product evaluations,"Journal of International Business Studies, 1982, pp. 89-99.

[2] Han. C. M.,"Country image: Halo or summary construct?" Journal of Marketing Research, 1989, 26, pp. 222-229.

[3] Dwyer, F. R., P. H. Schurr, and S. Oh,"Developing buyer-seller relationships," Journal of Marketing, 1987, 51(2), pp. 11-27.

[4] Grönroos, C.,"The marketing strategy continuum: towards a marketing concept for the 1990s," Management Decision, 1991, 29(1), pp. 7-13.

[5] Nagashima. Akira, "A comparison of Japanese and U.S. attitudes toward foreign products," Journal of Marketing, 1970 34, pp. 68-74.

[6] Narayana, C. L., "Aggregate images of American and Japanese products: implications on international marketing,"Columbia Journal of World Business, 1981, 16, pp. 31-35.

[7] Roth, M. S., and J. B. Romeo,"Matching product category and country image perceptions: A framework for managing Country-of-Origin effects,"Journal of International Business Studies, 1992, 23, pp. 477-479.

[8] Hong, S. T., and R. S. Wyer, "Effects of Country-of-Origin and product attribute information on product evaluation: An information processing perspective," Journal of Consumer Research, 1989, 16, pp. 174-187.

[9] Johansson, J. K., Douglas, S. P., andNonaka, I., “Assessing the impact of country of origin on product evaluations: A new methodological perspective. Journal of Marketing Research," 1985, 22(4), pp. 388-396.

[10] Han, C. M., andTerpstra, V.,"Country-of-Origin effect for Uni-National and Bi-National products,"Journal of International Business Studies, 1988, 19(2), pp. 235-253.

[11] Chao, P., "Partitioning Country-of-Origin effects: consumer evaluations of a hybrid product," Journal of International Business Studies, 1993, 24(2), pp. 291-307.

[12] Eng, T. Y., Ozdemir, S., and Michelson, G. (2016) "Brand origin and country of production congruity: Evidence from the UK and China." Journal of Business Research, 2016, 69(12), pp. 5703-5711.

[13] Gerstner, E.,"Do higher prices signal higher quality?”Journal of Marketing Research, 1985, 22(2), pp. 209-215. 
[14] Yavas, U., andAlpay, G.,"Does an exporting nation enjoy the same cross-national commercial image?" International Journal ofAdvertising, 1986, 5(2), pp. 109-120.

[15] Ahmed, Sadrudim. A., and Alain. d'Astous, "Cross-national evaluations of made-in concept using multiple cuesEuropean," Journal of Marketing, 1993, 27(7), pp. 39-52.

[16] Iyer, G. R., and J. K. Kalita,“The Impact of Country-of-Origin and Country-of-Manufacture clues on consumerperceptions of quality and Value,'Journal of Global Marketing, 1997, 11(1), pp. 7-28.

[17] Teas, R. K., andAgarwal, S.,"The effect of extrinsic product cues on consumers' perceptions of quality, sacrifice, and value," Journal of the Academy of Marketing Science, 2000, 28(2), pp. 278-90.

[18] Fishbein, Martin., andIsek, Ajzen, Belief, Attitude, Intention andBehavior: An Introduction to theory and research, MA: Addison-Wesley, 1975.

[19] Rosenberg, M. J., and C. I. Hanland, Cognitive, Affective, and Behavior Components of Attitudein Attitude Organization and Change: An Analysis of Consistency among Attitude Components. Eds. M. J. Rosenberg et al. New Haven, CT: Yale University Press, 1960.

[20] Kotler, Marketing Management, 10thed., Prentice-Hall International, Inc, 1999.

[21] Ladhari, R. and Michaud, M., "eWOM effects on hotel booking intentions, attitudes, trust, and website perceptions." International Journalof Hospitality Management, 2015, 46, pp. $36-45$.

[22] Kurman, J., "Self-enhancement, self-regulation, and self-improvement following failuresBritish,"Journal of Social Psychology, 2006, 45, pp. 339-356.
[23] Engel, J. F., Blackwell, R. D., andMiniard, P. W., Consumer Behavior, 6th ed., New York, NY: Dryden Press, 1984.

[24] Erciş, A., Ünal, S., Candan, F. B., andYıldırım, H., "The Effect of Brand Satisfaction, Trust and Brand Commitment on Loyalty and Repurchase Intentions." Procedia-Social and Behavioral Sciences, 2012, 58, pp. 1395-1404.

[25] Monroe, K. B., and Chapman, J. D.,"Framing effects on buyers subjective product evaluation," Advances in Consumer Research, 1987, 14, pp. 193-197.

[26] Zillmann, D., Mood Management: Using Entertainment to Full Advantages. In L. Donohew, H. E. Sypher, and E. T. Hyggins (Eds.), Communication, Social Cognition, and Affect. Hillsdale, NJ: Erlbaum, 1988, pp. 147-171.

[27] Knobloch, S., Mood Management Theory: Evidence, and Advancements. In J. Bryant and P. Vorderer (Eds.), Psychology of Entertainment. Mahwah, NJ: Lawrence Erlbaum Associates, 2006, pp. 239-254.

[28] Leary, M. R., andBaumeister, R. F., "The nature and function of self-esteem: sociometer theory," Advances in Experimental Social Psychology, 2000, 32, pp. 1-62.

[29] Eisingerich, A. B., Chun, H. H., Liu, Y., Jia, H. M., and Bell, S. J., "Why recommend a brand faceto-facebut not on Facebook? How word-of-mouth on online social sites differs from traditional word-ofmouth.”Journal of Consumer Psychology, 2015, 25, pp. 120-128.

[30] Sivanathan, N., and Pettit, N. C., "Protecting the through Consumption: Status goods as affirmational commodities," Journal of Experimental Social Psychology, 2010, 46, pp. 564-570. 